\section{Court ruling pleases UCSF}

\section{Berkeley}

The California Supreme Court relieved research universities of what they regarded as a potentially insurmountable burden in their continuing struggle with local residents seeking to block construction of new research facilities. The court ruled that the University of California at San Francisco (UCSF) did not have to prove that its new Laurel Heights building could not possibly represent a toxic hazard. Had the court decided otherwise, university officials throughout the state feared that they would be faced with an impossible burden of proof in similar cases.

UCSF bought its new research building in the Laurel Heights area of San Francisco in 1985, to relieve crowding on its main campus. Conversion of the space to research laboratories was halted in 1987 by a lawsuit filed by residential neighbours (see Nature 328, 656; 1987) who suspected that the new facility was potentially hazardous. UCSF had conducted environmental sampling studies on its main campus, which showed no increase in levels of toxic or radioactive chemicals in the vicinity of research buildings.

Those studies were used as evidence that there would be little risk at Laurel Heights. But local residents were satisfied, arguing that the absence of evidence that the emissions were harmful was not the same as proof that they are safe, and a local court agreed to stop the university's expansion plans.

The university appealed the case to the state supreme court, but in the meantime nearly 80,000 square feet of potential laboratory space remains empty, and the research groups already in the building are banned from using radioisotopes.

UCSF and other universities facing similar community opposition fear that the university would be given the impossible task of proving that all emissions were completely safe. "The scientific and biomedical world have been watching this case because of its implications for the future of research universities everywhere", said UCSF chancellor Julius Krevans.

Their fears were allayed with the court's acceptance of UCSF's risk assessment. But the university's troubles are not over. The court found that an environmental impact report that the university was required to produce did not adequately consider alternatives to the Laurel Heights building, nor did it adequately account for possible future uses of the building. A new report must be prepared and approved before the building conversion can continue.

Marcia Barinaga

\title{
Shortages of staff and money delay climate change predictions
}

\section{London}

BRITAIN's research into the greenhouse effect could be rapidly speeded up with an increase of resources. At the rate research is now proceeding, reliable predictions of regional climate change could be 20 or 30 years away, but the same results could be available within ten years if more research funds were available, according to David Carson, director of atmospheric sciences, at the Natural Environment Research Council (NERC). The country's research effort into the greenhouse effect was criticized last week by the science and technology spokesman for the Labour Party, Jeremy Bray. In an open letter to the prime minister Margaret Thatcher, he says there is no national research programme and no coherent participation in international progammes. But Alan Apling of the Department of the Environment says that only now is the science involved mature enough to facilitate coordination and this is beginning to happen very rapidly. Carson says there could be more national coordination, and he is working to that end, producing a strategy document for atmospheric sciences in Britain to be published next year. Andrew Gilchrist, director of research in the Meteorological Office, where the country's effort in global climatological modelling is concentrated, agrees that international links in this area are not adequate.

The prime minister is expected to re-

spond formally to Bray's criticisms soon Meanwhile, the announcement this week of a Christmas present to the NERC of $£ 1.05$ million may quieten for the moment those who claim that the government's voiced concern for the environment is not reflected in its actions. A substantial part of that money is expected to be directed to research on the greenhouse effect. And more resources for research in this area could be announced in the next few weeks when the government decides how to spend the extra money in next year's science budget. A major complaint of researchers studying the problems of manmade climate change is not one of money as much as one of staff shortages. Both at NERC and at the Meteorological Office there are difficulties in attracting good quality staff; some say this is a result of low salaries. But Andrew Gilchrist denies that the manpower shortage is as bad as it is made out to be. Though only the equivalent of one and a half people to work full time on climate modelling, there are enough back-up staff to keep the work at an international competitive standard. Researchers at the Meteorological Office do say though that work there is hindered by a shortage of computer time, and equipment to process the data the models produce. With the greenhouse effect now high on the list of government priorities, researchers now expect to receive more funds.

Christine McGourty

\section{Dingell castigates NIH over cut grants}

\section{Washington}

THE US National Institutes of Health (NIH) have been heavily criticized for taking "drastic action based solely on newspaper articles" on a case of alleged misconduct at Harvard Medical School when proper consideration was called for.

This charge is made in a stronglyworded letter from Congressman John Dingell to Otis Bowen, Secretary of Health and Human Services. Dingell, who heads the Energy and Commerce subcomittee on oversight and investigations, demands an immediate explanation why NIH decided to terminate two researchers' grants before they had conducted an investigation and when they had no evidence of wrongdoing beyond "two Boston Globe newspaper articles".

The case concerns two Harvard researchers, Scheffer Tseng and Kenneth Kenyon, who are alleged to have had business interests in an eye ointment they were responsible for testing and to have delayed publication of results showing the ointment to be ineffective (see Nature 336,
506; 6 December 1988).

Both researchers lost grants but, according to Dingell's letter, an unnamed high-level NIH official admitted that there had been no "NIH investigation ... no review of the extensive supporting documentation, no discussion of the Harvard interviews of the principals, and no NIH interviews of the principals". At the time the grants were cut, the NIH official had apparently not seen the reports from Harvard or from the hospital where the research had taken place, even though six weeks had passed since newspaper reports began to appear. Dingell's committee had earlier castigated NIH for its tardy investigations of scientific misconduct. Two congressional inquiries were held on scientific misconduct in April this year.

But Dingell writes that "summary action based purely on newspaper articles was not what we had in mind" in asking the Department of Health and Human Services to develop a "rapid, effective and fair" procedure for dealing with cases of alleged misconduct.
Alun Anderson 